\title{
Bond Strength of Zirconia to Different Core Materials
}

\author{
${ }^{1}$ Fabiana C Frattes, ${ }^{2} \mathrm{JB}$ Sorte de Oliveira, ${ }^{3}$ Cesar R Pucci, ${ }^{4}$ Alessandra B Borges, ${ }^{5} \mathrm{CR}$ Gomes Torres
}

\begin{abstract}
Background: Since bonding to zirconia is still questionable, the aim of this study was to evaluate the bond strength of yttrium-stabilized tetragonal zirconia polycrystal (Y-TZP) to different materials used to manufacture dental cores, employing a universal self-etching adhesive system.
\end{abstract}

Materials and methods: Cylinders obtained from blocks of Y-TZP Zirconia were sintered in a high-temperature oven. The surfaces to be bonded were blasted with aluminum oxide, then silica-coated aluminum oxide, and finally cleaned in ultrasonic bath. The specimens were divided into six groups according to the core material tested: Silver alloy (Ag/Sn/Cu, Tecnofix), copper alloy (Cu/Ni/Zn, Goldent LA), core buildup resin (Rebilda DC VOCO), Y-TZP zirconia (IPS e.max ZirCAD, Ivoclar Vivandent), enamel, and dentin. The zirconia cylinders were bonded to the core substrates using the Futurabond $U$ adhesive system (VOCO) and resinous cement (Bifix QM - VOCO). The specimens were shear tested in a universal testing machine at $1 \mathrm{~mm} /$ min. Data was analyzed using ANOVA and Tukey's test.

Results: Bond strength in MPa ( $\pm S D)$ for the different materials tested were dentin: (12.80 \pm 3.18$) a$; enamel: (15.13 \pm 3.09$)$ ab; resin: (17.20 \pm 4.67$) a b$; copper alloy: (18.93 \pm 4.66$) b c$; silver alloy: $(22.86 \pm 5.47)$ c; and zirconia: $(23.65 \pm 3.64)$ c. Groups followed by the same letters are not significantly different at $p<0.05$.

Conclusion: The metallic alloys and zirconia core materials showed significantly higher bond strength than those obtained directly on dentin. The core buildup resin bond strength to zirconia is similar to that obtained with enamel and dentin.

Keywords: Alloy, Dentin, Enamel, Shear bond strength, Zirconia.

How to cite this article: Frattes FC, de Oliveira JBS, Pucci CR, Borges AB, Torres CRG. Bond Strength of Zirconia to Different Core Materials. World J Dent 2016;7(4):169-174.

Source of support: Nil

Conflict of interest: None

\section{INTRODUCTION}

Ceramic materials have been widely used in restorative dentistry, especially in the last two decades, mainly

\footnotetext{
${ }^{1-5}$ Associate Professor

${ }^{1-5}$ Department of Restorative Dentistry, Institute of Science and Technology, São Paulo State University, São José dos Campos São Paulo, Brazil

Corresponding Author: CR Gomes Torres, Associate Professor Department of Restorative Dentistry, Institute of Science and Technology, São Paulo State University, São José dos Campos São Paulo, Brazil, e-mail: carlosrgt@fosjc.unesp.br
}

for their esthetic characteristics, which fulfilled patient demand for a metal-free material with good appearance. ${ }^{1,2}$ In this context, yttrium-stabilized tetragonal zirconia polycrystal (Y-TZP) holds a prominent position, featuring both good biocompatibility ${ }^{3,4}$ and excellent mechanical properties, the best reported among ceramics. Its high flexural resistance allows it to be characterized as being about six times stronger than feldspathic porcelain. ${ }^{5}$ It also shows high fracture resistance, ${ }^{6,7}$ good chemical and dimensional stability, high hardness, and high compression resistance. ${ }^{8,9}$

Zirconia has found various uses in the dental clinic e.g., in preparation of coping for crowns and as structures for all-ceramic prostheses, ${ }^{3,10}$ in the manufacturing of intracanal pins, ${ }_{1}^{11}$ as a material for inlay and onlay restorations, ${ }^{10}$ and even in the preparation of implants composed solely of zirconia. ${ }^{3}$

The most appropriate technique for performing an indirect restoration depends on the degree of coronary destruction. If there is a good amount of remaining enamel or dentin, the restoration can be cemented directly on those remaining coronal structures. Conversely, for the restoration of teeth that have undergone extensive destruction and show little remaining coronal structures, a foundation, namely the core, has to be placed within the tooth. This "simulates" dentin structure, aiming to provide retention and stability for the fixation and adaptation of the prosthetic crown. The core can be made of several materials. Choosing the most suitable material in each case depends on the state of the remaining dental structures as well as esthetic factors, cost, and clinical time. Some materials commonly used are metallic alloys, such as silver alloy or copper alloy. ${ }^{12}$ Another material used for reconstruction of the core is dual cure resin, which features similar elastic modulus to that of dentin. ${ }^{13}$ In recent years, all-ceramic restorations, i.e., those that employ only ceramic materials, even in the core, have become feasible. In this scenario, a zirconia core becomes an option, in particular for anterior teeth, since it has advantages in appearance when compared to metal cores and, in resistance, when compared with other ceramics. ${ }^{11,14}$

Though its mechanical and esthetic features position it as an excellent material for dental restorations, zirconia has been showing itself difficult to bond to, especially when compared to traditional ceramics, which contain silica in their composition. ${ }^{9,15-17}$ The application of hydrofluoric acid to create micromechanical retention 
is ineffective for this material, due to the absence of a vitreous phase. Applying a silane-based primer, which increases bonding in silica-based ceramics, also has no conditioning effect on untreated zirconia surfaces, precisely because of their low chemical reactivity. In recent years, different approaches to improve bonding to zirconia have been explored in the literature, such as the use of phosphate acid ester monomers (notably MDP), zirconate coupling agents, ${ }^{5}$ and organic silanes. ${ }^{18}$ In this sense, it is noteworthy that the purely chemical methods have shown little success in maintaining long-term bonding. Some experiments have shown that the bond strength of several compounds to zirconia decreases substantially after thermal cycling. ${ }^{5,15}$ To alleviate this problem, a common practice is to perform surface conditioning on zirconia before applying the adhesive system, using methods, such as sandblasting with aluminum oxide particles followed by silica coating ${ }^{18}$ and even plasma sprays. ${ }^{19}$

Previous studies on the bonding properties of zirconia have mostly focused on determining the bond strength between zirconia and the adhesive, and not in the efficacy or clinical applicability of a complete system, taking into account the presence of resinous cement in the interface. In particular, it has not been established which type of core material will make the zirconia-adhesive core system present the best clinical performance, especially regarding bonding. In this context, the ideal would be that different core materials would have proper bonding and that there would not be wide variations in the bond strength of zirconia to the different types of materials. However, since bonding to zirconia is notoriously difficult, some materials are expected to stand out. Thus, a study that investigates which material is best suited for the core when the crown is made of zirconia has immediate clinical applicability. Based on this, the aim of this study was to evaluate the bond strength of the zirconia-cement system to different core materials. The null hypothesis is that there are no significant differences on the bond strength of zirconia to the following materials: Dentin, enamel, composite resin, silver alloy, copper alloy, and zirconia.

\section{MATERIALS AND METHODS}

The experimental methodology employed was shear bond testing. Cylindrical zirconia specimens (acting as of crowns) were cemented over specimens of various materials commonly used as cores, as well as over enamel and dentin. Details on materials used are shown in Table 1.

\section{Specimen Preparation}

\section{Zirconia "Crown" Preparation}

To act as crowns, 72 cylindrical samples were obtained from a block of Y-TZP Zirconia (IPS e.max ZirCAD, B40L,
Table 1: Details about the materials used

\begin{tabular}{|c|c|c|c|}
\hline Material & Manufacturer & Ingredients & Batch \\
\hline $\begin{array}{l}\text { IPS e.max }{ }^{\circledR} \\
\text { ZirCAD }\end{array}$ & $\begin{array}{l}\text { Ivoclar Vivadent, } \\
\text { Schaan, } \\
\text { Liechtenstein }\end{array}$ & $\begin{array}{l}\text { Yttrium-stabilized } \\
\text { zirconium oxide }\end{array}$ & K54200 \\
\hline $\begin{array}{l}\text { Copper } \\
\text { alloy }\end{array}$ & $\begin{array}{l}\text { Goldent LA, } \\
\text { Cotia, SP, Brazil }\end{array}$ & Copper, Nickel, Zinc & N/A \\
\hline Silver alloy & $\begin{array}{l}\text { Tecnofix, São } \\
\text { Paulo, SP, Brazil }\end{array}$ & $\begin{array}{l}80 \% \text { Silver, } 17 \% \text { Tin, } \\
3 \% \text { Copper }\end{array}$ & $\mathrm{N} / \mathrm{A}$ \\
\hline Rebilda DC & $\begin{array}{l}\text { Voco, Cuxhaven, } \\
\text { Germany }\end{array}$ & $\begin{array}{l}\text { Bis-GMA, diurethane } \\
\text { dimethacrylate, BHT } \\
\text { and benzoyl peroxide }\end{array}$ & 1306479 \\
\hline $\begin{array}{l}\text { Futurabond } \\
\text { U }\end{array}$ & $\begin{array}{l}\text { Voco, Cuxhaven, } \\
\text { Germany }\end{array}$ & $\begin{array}{l}\text { MPP (methacryloy- } \\
\text { loxy propyl dihydro- } \\
\text { gen phosphate), } \\
\text { organic acids, (di) } \\
\text { methacrylates, } \\
\text { amines (DABE) } \\
\text { and BHT }\end{array}$ & 1307060 \\
\hline Bifix QM & $\begin{array}{l}\text { Voco, Cuxhaven, } \\
\text { Germany }\end{array}$ & $\begin{array}{l}\text { Bis-GMA, benzoyl } \\
\text { peroxide and amines }\end{array}$ & 1235174 \\
\hline
\end{tabular}

Ivoclar Vivadent, Schaan, Liechtenstein) using a diamond trephine mill with $2.67 \mathrm{~mm}$ of internal diameter. The samples were then sintered in a Sintramat high-temperature furnace (Ivoclar Vivadent, Schaan, Liechtenstein), resulting in specimens with a $2.22 \mathrm{~mm}$ of diameter and $2 \mathrm{~mm}$ height. A standardized surface conditioning of the samples was performed. The initial roughness was obtained by polishing with sandpaper (P120, P600, P800 and P1200, Extec, Enfield, CT, USA) using a circular polisher (DP-10, Panambra, São Paulo, Brazil). Subsequently, the surfaces to be bonded were sandblasted with $110 \mu \mathrm{m}$ aluminum oxide particles (Rocatec Pre, 3M/ESPE, St. Paul, MN, USA), under pressure of 2.8 bar, for 15 seconds, at a $10 \mathrm{~mm}$ distance, and a $90^{\circ}$ angle. The zirconia cylinders went through the process of silicatization, i.e., sandblasting with aluminum oxide particles coated with a thin layer of silicon dioxide (Rocatec Plus 3M/ESPE, St. Paul, MN, USA), with an average size of $110 \mu \mathrm{m}$, for 10 seconds, to induce the formation of tribochemical layer. All samples were cleaned in an ultrasonic bath for 20 seconds and air-dried.

\section{Core Material and Dental Structure Preparation}

Specimens were prepared to act as cores (or remaining dental structures, in the cases of dentin and enamel). Six different types of substrate assigned to experimental groups as described below $(\mathrm{n}=12)$.

1. Silver alloy $(A g)$ : Cylindrical specimens with diameter $6 \mathrm{~mm}$ and height $2 \mathrm{~mm}$ were prepared using an alloy containing silver, tin, and copper (Technofix, São Paulo, Brazil). 
2. Copper alloy $(\mathrm{Cu})$ : Cylindrical specimens $(6 \times 2 \mathrm{~mm})$ were prepared from one alloy containing copper, nickel, and zinc (Goldent LA, Cotia, São Paulo, Brazil).

3. Resin (Rebilda): Cylindrical specimens were prepared with the aid of a silicone mold $(6 \times 2 \mathrm{~mm})$ using a dual resin filling material (Rebilda DC, VOCO, Cuxhaven, Germany) applied in a single layer and light cured for 20 seconds, using a light-emitting diode (LED) curing light (Emitter-A, Schuster, Santa Maria, RS, Brazil) with a $550 \mathrm{~mW} / \mathrm{cm}^{2}$ power density.

4. Zirconia (Zr): Cylindrical specimens were obtained from blocks of Y-TZP zirconia (IPS e.max ZirCAD, model B40L, Ivoclar Vivadent, Schaan, Liechtenstein), using a diamond trephine mill with $5.8 \mathrm{~mm}$ of internal diameter, resulting in specimens with $6.4 \mathrm{~mm}$ of diameter and $2.6 \mathrm{~mm}$ height. These specimens were sintered as described above, resulting in samples with $4.8 \mathrm{~mm}$ of diameter and $2 \mathrm{~mm}$ height postsintered.

5. Enamel: Specimens were obtained from sound bovine incisors, freshly extracted, cleaned, and stored in deionized water under refrigeration until the moment they were used. The roots were removed via a crosssectional cut below the cementoenamel junction using a double-sided diamond disk (KG Sorensen, Barueri, São Paulo, Brazil). The labial surfaces were flattened using P400-SiC sandpaper (Extec, Enfield, CT, USA) under water cooling. A surface of approximately $6 \times 6$ $\mathrm{mm}$ was exposed using the circular polisher.

6. Dentin: The specimens were prepared in an identical manner to that used for the enamel group, except that a flat dentin surface of approximately $6 \times 6 \mathrm{~mm}$ was obtained.

\section{Specimens Mounting Procedure}

After going through the procedures described above, specimens of the six groups were embedded in 72 PVC tubes with $25 \mathrm{~mm}$ of diameter and $30 \mathrm{~mm}$ height (Amanco, São Paulo, Brazil), specially cut for the purpose of adapting the specimens to the shear testing machine. The tubes were placed within a silicone matrix with the same dimensions, which provided a seating surface for the samples. The specimens of all groups were then inserted into the tubes, which were filled with acrylic resin (Jet, Articles Dental Classic, Campo Limpo, São Paulo, Brazil). After resin polymerization, the specimens were polished with P-600 sandpaper, applying a load of $436 \mathrm{~g} / \mathrm{min}$ for 1 minute, to standardize the surface texture of the materials to be bonded, as recommended in ISO TR 11405: 2003. ${ }^{20}$

\section{Cementation Procedure}

The conditioned zirconia cylinders (acting as prosthetic crowns) were bonded to the specimens that simulated cores using the Futurabond U (VOCO, Cuxhaven, Germany) universal adhesive system in self-etch mode. The adhesive was applied according to the manufacturer's recommendations, on the core materials and zirconia cylinders, for 20 seconds, followed by 5 seconds of air blast, and light curing for 10 seconds.

Then, Bifix QM resin cement (VOCO) was applied on the treated surface of the zirconia cylinders, which were then positioned over the core material. A $100 \mathrm{gm}$ load was applied for 4 minutes. After removing the excesses with a disposable applicator, the cement was light-cured for 20 seconds each on opposite sides. After cementation, all specimens were stored in deionized water for 1 week in order to allow for postcuring of the resinous material.

\section{Shear Bond Strength Test}

The specimens were shear tested in a Universal Testing Machine (DL 200MF, EMIC, São José dos Pinhais, PR, Brazil), with a $50 \mathrm{~kg}$ load cell at a speed of $1 \mathrm{~mm} / \mathrm{min}$. The specimens were fixed on a metal base designed for correctly positioning them inside the testing machine, and then a steel knife-edge was placed over the specimen so that the shear force was directed along the bonded surface. The data was subjected to one-factor Analysis of Variance (ANOVA) followed by Tukey's test. The significance level was $5 \%$.

\section{RESULTS}

Variance analysis shows a value of $\mathrm{p}=0.001(\mathrm{~F}=12.372$, $5^{\circ}$ of freedom), which allows the rejection of the null hypothesis and the assumption that there are significant differences among the groups. The results of Tukey's test are presented in Table 2 .

The bond strength values of the core material represented by silver and copper alloys, as well as zirconia, showed significantly higher means than those obtained for dentin. In addition, no significant differences were found among the mean bond strength of dentin, enamel, and resin groups.

In Graph 1 it is possible to visually compare the mean bond strength values for the different groups.

Table 2: Mean ( \pm standard deviation) of the shear bond strength and Tukey's test results

\begin{tabular}{llllll}
\hline Groups & Mean (MPa) & Standard deviation & Homogeneous sets \\
\hline Dentin & 12.80 & \pm 3.18 & $\mathrm{~A}$ & & \\
Enamel & 15.13 & \pm 3.09 & $\mathrm{~A}$ & $\mathrm{~B}$ & \\
Rebilda & 17.20 & \pm 4.67 & $\mathrm{~A}$ & $\mathrm{~B}$ & \\
Cu alloy & 18.93 & \pm 4.66 & & $\mathrm{~B}$ & $\mathrm{C}$ \\
Ag alloy & 22.86 & \pm 5.47 & & & $\mathrm{C}$ \\
Zirconia & 23.65 & \pm 3.64 & & & $\mathrm{C}$ \\
\hline
\end{tabular}

*Means followed by the same letters are not significantly different at $p<0.05$. 


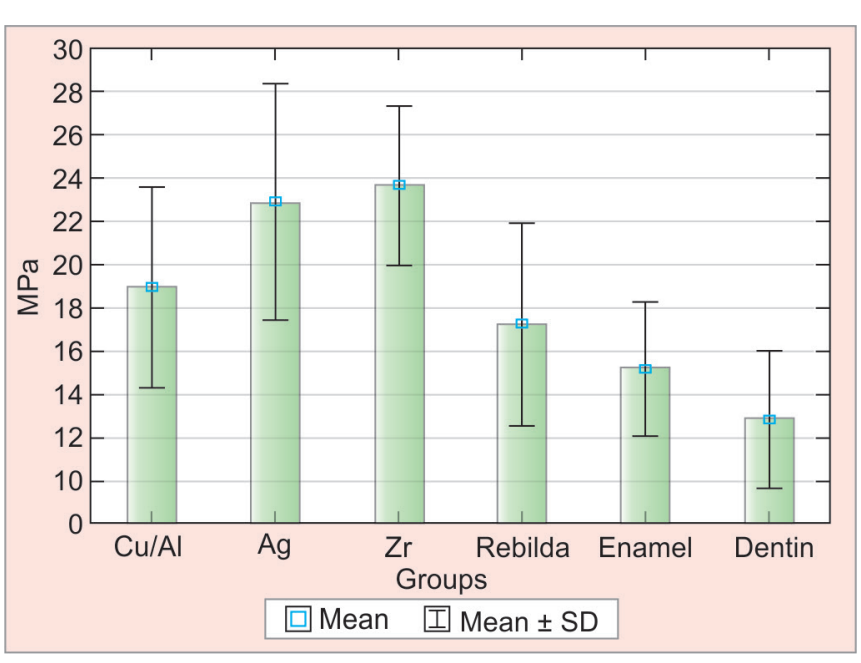

Graph 1: Mean shear bond strength SD obtained by the tested groups

\section{DISCUSSION}

Esthetic and physical characteristics of Y-TZP zirconia have led to a surge of interest in this material, as well as the increase of its use in dental clinic. Zirconia has found applications even in posterior teeth crowns, ${ }^{21,22}$ where the mechanical loads are higher. As its resistance to fracture after thermal treatment is comparable to that of steel, ${ }^{23}$ its use as a core material has also been investigated.

The existing literature has considered zirconia not only as a promising material, but also as one that is difficult to bond to. ${ }^{9,15-17,24,25}$ As it is essentially inert and nonpolar, chemical conditioning techniques commonly used in ceramics that have silica in their composition are ineffective on zirconia surfaces, unless they are pretreated. ${ }^{9}$ In this sense, various methods to increase mechanical retention have been investigated. ${ }^{26,27}$ It has been reported that the method employed in this study, blasting the zirconia surface with aluminum oxide particles, followed by silicatization, i.e., blasting with alumina particles coated with a silica layer, and finally by silane application, significantly improves bonding. ${ }^{25,27-29}$

When sandblasted with high-speed alumina particles, a zirconia surface loses material in a relatively even way, which causes an increase of its roughness, and thus of its contact area, allowing for a better flow of the luting material and providing micromechanical interlock. ${ }^{29}$ When the alumina particles are coated with silica, in addition to the roughening, silicon dioxide molecules from the sand particles are transferred to the zirconia surface. The impregnation depth may reach up to $15 \mu \mathrm{m}$, forming silica islands which are fused to the zirconia surface. Silane molecules, which are part of the Futurabond $U$ adhesive system, provide a chemical interface between the silica fused to the zirconia surface and the resin cement. As the alkoxy group (of the silane molecule) chemically bonds to silicatized surface, the methacrylate group can copolymerize with the resins in the cement. ${ }^{9}$

Previous studies have shown that the bond strength to zirconia depends on the adhesive system used. ${ }^{30,31}$ Although studies using the system chosen here (Futurabond $\mathrm{U}$ ) for bonding to zirconia have not been found for a direct comparison, given that it is a fairly recent material, the results presented here can be compared to other studies that used adhesive systems with similar chemical composition, i.e., adhesives which have organic phosphate acid monomers as ingredients. ${ }^{28,31,32}$

The zirconia-zirconia shear bond strength was the largest found in the present study. In addition to the conditioning performed on the surface, another reason for, i.e., the presence of a phosphate monomer in the adhesive system, since the monomer's phosphate ester group binds directly to metallic oxides, including zirconium oxide. ${ }^{33}$ The zirconia-zirconia group also had the lowest variance-to-mean ratio. As the two interfaces involved are between cement and zirconia and the specimens were treated similarly, both interfaces are expected to bond in a very homogeneous way.

On the contrary, the lowest bond strength was found between dentin and zirconia. That, however, is more a reflex of the general difficulty of bonding to dentin, ${ }^{34}$ which is caused by its high organic content and humidity, ${ }^{35,36}$ than any factor related specifically to zirconia. That is, although it was low compared to other substrates, one cannot say that bonding to dentin has been inadequate. However, a recent study on the bonding of universal adhesives to dentin, including Futurabond U, used in this study, confirmed that the bond strength is independent of application mode (self-etching and etchand-rinse) and remains high even after thermal cycling, suggesting that its use is appropriate in different clinical conditions. $^{37}$

The mean bond strength to enamel was slightly, but not significantly, higher than that to dentin. The adhesion mechanism to both substrates is quite similar and involves mechanical and chemical factors. Mechanically, in the presence of the acid contained in the adhesive system, the minerals in the hard tissues are removed and replaced by resin monomers which, by diffusion, infiltrate the porosities created by the absence of mineral, generating micromechanical retention after polymerization..$^{38}$ Chemically, the phosphate functional monomers in the adhesive system bond ionically to calcium of hydroxyapatite, forming calcium phosphate, along with a limited surface-decalcification effect. ${ }^{38}$ Regarding dentin, it is interesting to note that by having moderate acidity $(\mathrm{pH} \approx 2),{ }^{37}$ the Futurabond $\mathrm{U}$ adhesive system, when applied in self-etch mode, causes the formation of a much thinner hybrid layer than that which is obtained 
when more acidic adhesives or etch-and-rinse mode are employed, but the thickness of the hybrid layer seems to have no importance for the bonding effectiveness. On the contrary, when the surface is only slightly demineralized, moderate acidity adhesive systems preserve the collagen, keeping it encapsulated in a protective layer of hydroxyapatite. ${ }^{38}$

The mean bond strength of the Rebilda DC dual resin was better than that of enamel, but not significantly higher. The bonding mechanism is essentially polymerization based: The greater the occurrence of copolymerization between the cement monomers and the resin at the interface, the greater the bond strength. In addition to light exposure, the polymerization reaction is accelerated by the presence of co-initiators that promote bonding of resin luting agents present both in the cement and in Rebilda to the adhesive layer. ${ }^{39,40}$

Both alloys used had significantly better bond strength than dentin. This performance may be attributed the chemical interaction between the phosphate of the functional monomer and the metallic ions. ${ }^{15}$ This result is particularly interesting because it suggests that in teeth with little remaining coronal structures or other situations in which the most suitable core is a metallic one, clinicians can use zirconia crowns. Furthermore, in a clinical situation, should it be necessary to replace a crown already installed over a metallic core, and zirconia is being considered as the material for the new crown, there is no need to replace the core itself.

Within the limitations of this study, it was observed that the bond strength of zirconia to all tested substrates was equal to or higher than that to dentin, which constitutes the core of a healthy tooth after preparation. Clinical studies have reported high success rates in indirect restorations with zirconia, including in crowns installed directly over dentin. ${ }^{41,42}$ It is therefore expected that the success in bonding zirconia to the various materials studied in the present study will be reproduced clinically.

\section{CONCLUSION}

Among the core materials tested, the one that best bonded to zirconia was zirconia itself. It would probably be the core material of choice in clinical cases where crown retention must be improved, followed closely by silver alloys. All materials tested bonded similarly (enamel, Rebilda) or better (copper and silver and zirconia) to zirconia than dentin.

\section{REFERENCES}

1. Kelly JR, Nishimura I, Campbell SD. Ceramics in dentistry: Historical roots and current perspectives. J Prosthet Dent 1996 Jan;75(1):18-32.
2. Heikkinen TT, Matinlinna JP, Vallittu PK, Lassila LV. Dental zirconia adhesion with silicon compounds using some experimental and conventional surface conditioning methods. Silicon 2009 Jul;1(3):199-202.

3. Manicone PF, Rossi Iommetti P, Raffaelli L. An overview of zirconia ceramics: basic properties and clinical applications. J Dent 2007 Nov;35(11):819-826.

4. Piconi C, Maccauro G. Zirconia as a ceramic biomaterial. Biomaterials 1999 Jan;20(1):1-25.

5. Yoshida K, Tsuo Y, Atsuta M. Bonding of dual-cured resin cement to zirconia ceramic using phosphate acid ester monomer and zirconate coupler. J Biomed Mater Res B Appl Biomater 2006 Apr;77(1):28-33.

6. Chekhani UN, Mikeli AA, Huettig FK. All-ceramic prosthetic rehabilitation of a worn dentition: use of a distal cantilever. Two-year follow-up. Dent Res J 2013 Jan;10(1):126-131.

7. Stawarczyk B, Özcan M, Hämmerle CH, Roos M. The fracture load and failure types of veneered anterior zirconia crowns: an analysis of normal and Weibull distribution of complete and censored data. Dent Mater 2012 May;28(5):478-487.

8. Guazzato M, Albakry M, Ringer SP, Swain MV. Strength, fracture toughness and microstructure of a selection of allceramic materials. Part II. Zirconia-based dental ceramics. Dent Mater 2004 Jun;20(5):449-456.

9. Thompson JY, Stoner BR, Piascik JR, Smith R. Adhesion/ cementation to zirconia and other non-silicate ceramics: Where are we now? Dent Mater 2011 Jan;27(1):71-82.

10. Ardlin BI. Transformation-toughened zirconia for dental inlays, crowns and bridges: chemical stability and effect of low-temperature aging on flexural strength and surface structure. Dent Mater 2002 Dec;18(8):590-595.

11. Koutayas SO, Kern M. All-ceramic posts and cores: the state of the art. Quintessence Int 1999 Jun;30(6):383-392.

12. Scolaro J, Valle A, Bonfante G, Diniz D. Evaluation of the traction resistance of cast crowns cemented on rigid and cast post reconstructed teeth. Braz Dent Sci 2010 Apr-Jun;6(2): 12-19.

13. Aksornmuang J, Foxton RM, Nakajima M, Tagami J. Microtensile bond strength of a dual-cure resin core material to glass and quartz fibre posts. J Dent 2004 Aug;32(6):443-450.

14. Aboushelib MN, Kleverlaan CJ, Feilzer AJ. Microtensile bond strength of different components of core veneered all-ceramic restorations: Part II: Zirconia veneering ceramics. Dent Mater 2006 Sep;22(9):857-863.

15. Kern M, Wegner SM. Bonding to zirconia ceramic: adhesion methods and their durability. Dent Mater 1998 Jan;14(1):64-71.

16. Piascik JR, Wolter SD, Stoner BR. Development of a novel surface modification for improved bonding to zirconia. Dent Mater 2011 May;27(5):e99-e105.

17. Aboushelib MN, Matinlinna JP, Salameh Z, Ounsi H. Innovations in bonding to zirconia-based materials: Part I. Dent Mater 2008 Sep;24(9):1268-1272.

18. Matinlinna JP, Heikkinen T, Özcan M, Lassila LV, Vallittu PK. Evaluation of resin adhesion to zirconia ceramic using some organosilanes. Dent Mater 2006 Sep;22(9):824-831.

19. Derand T, Molin M, Kvam K. Bond strength of composite luting cement to zirconia ceramic surfaces. Dent Mater 2005 Dec;21(12):1158-1162.

20. ISO T. 11405. Dental materials - Testing of adhesion to tooth structure. 2003:1-10.

21. McLaren EA, White SN. Glass-infiltrated zirconia/aluminabased ceramic for crowns and fixed partial dentures: 
clinical and laboratory guidelines. Quintessence Dent Technol 2000;23:63-76.

22. Suarez M, Lozano J, Paz SM, Martinez F. Three-year clinical evaluation of In-Ceram Zirconia posterior FPDs. Int J Prosthodont 2004 Jan-Feb;17(1):35-38.

23. Coelho P, Bonfante E, Silva N, Rekow E, Thompson V. Laboratory simulation of Y-TZP all-ceramic crown clinical failures. J Dent Res 2009 Apr;88(4):382-386.

24. Özkurt Z, Kazazoglu E, Ünal A. In vitro evaluation of shear bond strength of veneering ceramics to zirconia. Dent Mater J 2010 Mar;29(2):138-146.

25. Amaral M, Belli R, Cesar PF, Valandro LF, Petschelt A, Lohbauer $\mathrm{U}$. The potential of novel primers and universal adhesives to bond to zirconia. J Dent 2014 Jan;42(1):90-98.

26. Blatz MB, Sadan A, Kern M. Resin-ceramic bonding: A review of the literature. J Prosthet Dent 2003 Mar;89(3):268-274.

27. Inokoshi M, De Munck J, Minakuchi S, Van Meerbeek B. Meta-analysis of bonding effectiveness to Zirconia ceramics. J Dent Res 2014 Apr;93(4):329-334.

28. Han I-H, Kang D-W, Chung C-H, Choe H-C, Son M-K. Effect of various intraoral repair systems on the shear bond strength of composite resin to zirconia. J Adv Prosthodont 2013 Aug;5(3):248-255.

29. Mehta D, Shetty R. Bonding to zirconia: elucidating the confusion. Int Dent SA 2010;12(2):46-52.

30. Turker S, Ozcan M, Mandali G, Damla I, Bugurman B, Valandro L. Bond strength and stability of 3 luting systems on a zirconia-dentin complex. Gen Dent 2012 Nov-Dec;61(7): e10-13.

31. Bottino M, Bergoli C, Lima E, Marocho S, Souza R, Valandro L. Bonding of Y-TZP to dentin: effects of Y-TZP surface conditioning, resin cement type, and aging. Oper Dent 2014 May-Jun; 39(3):291-300.

32. Kim B-K, Bae HE-K, Shim J-S, Lee K-W. The influence of ceramic surface treatments on the tensile bond strength of composite resin to all-ceramic coping materials. J Prosthet Dent 2005 Oct;94(4):357-362.

33. Wolfart M, Lehmann F, Wolfart S, Kern M. Durability of the resin bond strength to zirconia ceramic after using different surface conditioning methods. Dent Mater 2007 Jan;23(1): 45-50.

34. Carvalho R, Pegoraro T, Tay F, Pegoraro L, Silva N, Pashley D. Adhesive permeability affects coupling of resin cements that utilise self-etching primers to dentine. J Dent 2004 Jan;32(1):55-65.

35. Abo-Hamar SE, Hiller K-A, Jung H, Federlin M, Friedl K-H, Schmalz G. Bond strength of a new universal self-adhesive resin luting cement to dentin and enamel. Clin Oral Investig 2005 Sep;9(3):161-167.

36. Pashley D, Carvalho R. Dentine permeability and dentine adhesion. J Dent 1997 Sep;25(5):355-372.

37. Wagner A, Wendler M, Petschelt A, Belli R, Lohbauer U. Bonding performance of universal adhesives in different etching modes. J Dent 2014 Jul;42(7):800-807.

38. Van Meerbeek B, Yoshihara K, Yoshida Y, Mine A, De Munck J, Van Landuyt KL. State of the art of self-etch adhesives. Dent Mater 2011 Jan;27(1):17-28.

39. Arrais CA, Giannini M, Rueggeberg FA, Pashley DH. Microtensile bond strength of dual-polymerizing cementing systems to dentin using different polymerizing modes. J Prosthet Dent 2007 Feb;97(2):99-106.

40. Bitter K, Gläser C, Neumann K, Blunck U, Frankenberger R. Analysis of resin-dentin interface morphology and bond strength evaluation of core materials for one stage postendodontic restorations. PloS One 2014 Feb;9(2):e86294.

41. Örtorp A, Kihl ML, Carlsson GE. A 5-year retrospective study of survival of zirconia single crowns fitted in a private clinical setting. J Dent 2012 Jun;40(6):527-530.

42. Al-Amleh B, Lyons $\mathrm{K}$, Swain M. Clinical trials in zirconia: A systematic review. J Oral Rehabil 2010 Aug;37(8):641-652. 